\title{
Shared care joint working group report
}

\section{The Royal College of Psychiatrists and The Royal College of General Practitioners}

\section{Summary}

In 1991 a Shared Care Joint Working Group was established between The Royal College of General Practitioners and The Royal College of Psychiatrists under the co-chairmanship of Dr Alistair F. Wright and Dr Douglas G. Fowlie. The aim of the working group was to produce a consensus statement on shared care of mentally ill patients focusing on the management of patients' problems by general practice and mental health care teams. It was recognised that psychiatry and general practice share an interest in treating the whole patient and that developments in community psychiatry and primary care had melted the boundaries between general practitioners and psychiatrists. The recent rapid expansion of community care had also led to increasing numbers of patients with long-term mental illness living in the community and seeking care from their family doctor. The reorganisation in contractual and funding arrangements within the National Health Service was underpinning new management structures and the relatively unknown impact of general practice fundholding was having an effect on meeting needs generated by mental illness.

Both Colleges acknowledged that these changes had altered the traditional working relationships between primary and specialty care.

The report considers psychiatric consultation in general practice, shared care with particular reference to depression, long-term mental illness, elderly patients with mental illness and individuals with learning disabilities. It acknowledges the many components of a comprehensive psychiatric service and notes the important links between specialties within psychiatry, but focuses on the main areas in which primary medical and mental health care teams collaborate.

The conclusions include recommendations that there are advantages to patients when catchment services are aligned with general practices, especially when consultant psychiatrists develop liaison links and see patients in health centres or surgeries.

The report promotes the benefits of face to face contact between the psychiatrist and general practitioner and community psychiatric team and primary health care team to produce mutual understanding and shared assessment, management and decision making on behalf of patients. It confirms that good practice is enhanced when psychiatric teams become familiar with the social and community components of their catchment population environment. Closer integration of training for general practitioners and psychiatrists is commended and the group encourage the establishment of both joint audit and practice based disease registers for patients with long-term mental illnesses.

The Joint Working Group tackled an important topic. This report is fully referenced and contains useful summaries and guidance for both clinical teams in primary and specialty settings and managers of services.

It is published jointly under the auspices of both colleges (in press).

DOUGLAS G. FoWLIE

\section{Trainees' day}

The Southern Division of the Collegiate Trainees' Committee is holding a Trainees' Day at Sutton Hospital, Surrey on 14 July 1993. Topics will include: presentation skills, research methodology, enhancing your CV, getting your paper published, and getting your next job. Attendance is free and refreshments and lunch will be provided. Further information: Dr Mary Cameron, Senior Registrar in Child Psychiatry, Department of Child \& Adolescent Psychiatry, Queen Mary's Hospital for Children, Carshalton, Surrey SM5 4NR. 